\title{
Increased Sensitivity of Gastric Acid Secretion to Gastrin in Cirrhotic Patients with Portacaval Shunt
}

\author{
H. Jürgen Lenz, Thomas Struck, Heiner Greten, Michael A. Koss, Viktor E. Eysselein, John H. Walsh, and Jon I. Isenberg \\ Medizinische Kernklinik und Poliklinik, Universitätskrankenhaus Eppendorf, Universität Hamburg, Hamburg, Federal Republic \\ of Germany; Divisions of Gastroenterology, Departments of Medicine, University of California, San Diego Medical Center, \\ San Diego, California 92103; Veterans Administration Medical Center, San Diego, California 92161; and Center for Ulcer \\ Research and Education, Veterans Administration Medical Center Wadsworth, Los Angeles, California 90073
}

\begin{abstract}
We studied acid secretory responses to exogenous pentagastrin and to exogenous and endogenous gastrin in 12 stable cirrhotic subjects with portacaval shunt, 12 unshunted cirrhotics, and 12 normal subjects. Basal and stimulated serum gastrin concentrations as well as basal and maximum acid outputs were similar in the three groups. At low doses of either exogenous pentagastrin or gastrin-17 (G17), cirrhotics with portacaval shunt secreted significantly greater amounts of gastric acid than unshunted subjects. After low doses of intragastric peptone, cirrhotics with portacaval shunt secreted significantly more acid than unshunted cirrhotics and normal subjects. At each measured serum gastrin concentration after either exogenous $\mathbf{G 1 7}$ or intragastric peptone meals, cirrhotics with portacaval shunt secreted more acid than the unshunted control groups and their dose-response curve was significantly shifted to the left. Thus, in cirrhotic patients with portacaval shunt, gastric acid secretion is abnormally sensitive to both exogenously administered or endogenously released gastrin.
\end{abstract}

\section{Introduction}

The major life-threatening complication of cirrhosis of the liver is upper gastrointestinal bleeding due to esophageal bleeding or peptic ulcer (1). In order to prevent recurrent bleeding from esophageal varices, various types of surgical procedures to decompress the portal circulation have been utilized; the most common of these is the portacaval shunt (2). After portacaval shunt in dog, gastric acid secretion increased both in the basal state and in response to enteral and parenteral stimulants (35). The effects of portacaval shunt on basal and maximal acid secretion in humans reveal conflicting observations; some report no change (6), and others an increase (7). Although acid secretion in the presence of intragastric meals has not been tested in cirrhotic subjects, jejunal distension with a meal or a balloon sig-

A part of this study was presented at the annual meeting of the American Gastroenterological Association, May 1983, in Washington, D.C., and was published in abstract form (1983. Gastroenterology. 84:1227).

Address correspondence to Dr. Lenz at Medizinische Kernklinik und Poliklinik, Universitätskrankenhaus Eppendorf, Universität Hamburg, Martinistr. 52, 2000 Hamburg 20, Federal Republic of Germany.

Received for publication 28 August 1986 and in revised form 12 November 1986

J. Clin. Invest.

(c) The American Society for Clinical Investigation, Inc.

0021-9738/87/04/1120/05 $\$ 1.00$

Volume 79, April 1987, 1120-1124 nificantly increased gastric acid secretion in those with a portacaval shunt $\left(+\mathrm{PCS}_{\mathrm{c}}\right){ }^{1}$, while in normal subjects $(\mathrm{N})$ or unshunted cirrhotics $\left(-\mathrm{PCS}_{\mathrm{c}}\right.$ ) jejunal distension was without effect $(6,8)$. The mechanism responsible for altered secretory responses in humans after portacaval shunt is unknown.

During a series of experiments designed to examine the effects of nutrient and nonnutrient jejunal meals in $+\mathrm{PCS}_{\mathrm{c}}$ and $-\mathrm{PCS}_{\mathrm{c}}$ (8), we observed that gastric acid secretion in $+\mathrm{PCS}_{\mathrm{c}}$ was much more sensitive to intravenous infusion of the $\mathrm{COOH}$-terminal pentapeptide of gastrin, pentagastrin, than $-\mathrm{PCS}_{\mathrm{c}}$ and $\mathrm{N}(9)$. Since gastrin fragments containing less than eight amino acids are preferentially inactivated during hepatic transit (10), the differences between $+\mathrm{PCS}_{\mathrm{c}}$ and $-\mathrm{PCS}_{\mathrm{c}}$ may have been secondary to higher blood levels of pentagastrin in the shunted group. Therefore, the purpose of this study was to determine whether $+\mathrm{PCS}_{\mathrm{c}}$ were more sensitive to endogenously released gastrin or to an exogenous gastrin, which is not preferentially metabolized in the liver (10), compared with $-\mathrm{PCS}_{\mathrm{c}}$ as well as $\mathrm{N}$.

\section{Methods}

Subjects. 12 patients with histologically documented cirrhosis, nine males and three females, their mean age $59 \mathrm{yr}$ (range: 45 to $72 \mathrm{yr}$ ), were studied. Portacaval shunt, nine side-to-side and three end-to-side, had been performed for bleeding of esophageal varices $6 \mathrm{mo}$ to $6 \mathrm{yr}$ earlier. Shunt patency was confirmed by angiography within the preceding $12 \mathrm{mo}$. Since the $+\mathrm{PCS}_{\mathrm{c}}$ group contained two variables regarding their health status, cirrhosis of the liver and portacaval shunt, two additional groups served as controls. 12 stable $-\mathrm{PCS}_{\mathrm{c}}$, nine males and three females, their mean age $59 \mathrm{yr}$ (range: 44 to $71 \mathrm{yr}$ ), were studied. In nine, the diagnosis of cirrhosis has been established by needle biopsy of the liver, in three by clinical findings including prior jaundice, ascites, endoscopic demonstration of esophageal varices, and other features of Laennec's cirrhosis (11). The $+\mathrm{PCS}_{\mathrm{c}}$ and $-\mathrm{PCS}_{\mathrm{c}}$ had a past history of ethanol abuse. At the time of study, all were outpatients, free of jaundice, clinical evidence of ascites, encephalopathy, and in good health. Ethanol intake was denied and none showed any evidence of alcohol intake during the study period. 12 normal subjects, nine males and three females, their mean age $58 \mathrm{yr}$ (range: 41 to $70 \mathrm{yr}$ ), were also studied. None of the 36 subjects had a history to suggest peptic ulcer disease, and none took any medication on a regular basis or within $48 \mathrm{~h}$ before the study. Biochemical parameters including serum bilirubin, albumin, total protein, alkaline phosphatase, and prothrombin time were similar in the three groups. Only the serum glutamic oxaloacetic transaminase was significantly $(P<0.05)$ elevated

1. Abbreviations used in this paper: $\mathrm{EC}_{50}$, plasma gastrin concentration, which results in one-half maximal acid secretion; $\mathrm{ED}_{\mathbf{5 0}}$, dose that induces one-half maximal acid secretion: $E_{50 c}, E_{50}$ corrected for basal acid secretion; G17, human synthetic heptadecapeptide gastrin-17; N, normal subjects; + PCS, , cirrhotic patients with portacaval shunt; - PCS $_{c}$, cirrhotic patients without portacaval shunt. 
in cirrhotics compared with $\mathrm{N}:+\mathrm{PCS}_{\mathrm{c}}, 47 \pm 6 \mathrm{U} /$ liter; $-\mathrm{PCS}_{\mathrm{c}}, 51 \pm 8 \mathrm{U} /$ liter; and N, 15 $\pm 1 \mathrm{U} /$ liter.

Experiments were approved by the Human Subjects Committee, University of California, San Diego on February 11, 1982 and by the Ethik Kommission, Universität Hamburg, on November 19, 1985. Written informed consent was obtained from each individual. Human synthetic heptadecapeptide gastrin-I (G17) was given under investigational new drug No. 10,872 from the U.S. Food and Drug Administration, Washington, D.C.

Measurement of acid secretion in response to pentagastrin and G17. After a 12-h overnight fast, a double-lumen radiopaque nasogastric tube (model AN 10; H. W. Andersen Products Inc., Oyster Bay, NY) was fluoroscopically positioned with the tip in the gastric antrum. Residual gastric juice was aspirated for $15 \mathrm{~min}$ and discarded. Basal secretion was collected for two 15 -min periods by continuous suction at -5 to -10 mmHg using a Stedman vacuum pump (model 2590 B; American Cystoscope Makers Inc., New York, NY). To maintain patency the tube was manually flushed with $10-20 \mathrm{ml}$ of air and aspirated by hand at 5min intervals. The volume of gastric juice was measured to the nearest milliliter. Hydrogen ion concentration was determined in vitro by automatic titration of a $0.2-\mathrm{ml}$ aliquot with $0.2 \mathrm{M} \mathrm{NaOH}$ to pH 7.0 (Radiometer, Copenhagen, Denmark) (12).

After collecting basal secretions for $30 \mathrm{~min}$, gastric acid secretion was measured in response to either graded doses of pentagastrin (Peptavlon; Ayerst Laboratories, New York, NY) or to graded doses of synthetic human gastrin 17-I (G17) (Research Plus Inc., Bayonne, NJ). On one day, graded doses of pentagastrin $(23.4,93.8,375,1,500$, and 6,000 $\mathrm{ng} / \mathrm{kg}$ per $\mathrm{h})$, and on another day, graded doses of G17 $(2.34,9.38,37.4$, 150 , and $600 \mathrm{pmol} / \mathrm{kg}$ per $\mathrm{h}$ ) were intravenously infused for $30 \mathrm{~min}$ by an infusion pump (model 975; Harvard Apparatus Co., Inc., Millis, MA) in a stepwise fashion. Previous experiments indicated that gastric acid secretion did not significantly differ whether the doses of pentagastrin or of G17 were given sequentially on a single day or individually on separate days $(13,14)$.

Measurement of acid secretion in response to peptone. On a separate day and after measuring basal secretion for $30 \mathrm{~min}$, liquid test meals, $500 \mathrm{ml}$ each, containing peptone (Bacto-Peptone; Difco Laboratories, Detroit, MI) were given in increasing order of concentration $(0,0.5,1.0$, $2.0,4.0$, and $8.0 \% \mathrm{wt} / \mathrm{vol}$ ) adjusted to $310 \mathrm{mosmol} / \mathrm{kg}$ and $\mathrm{pH} 7.0$ by the addition of $\mathrm{NaCl}$ and $4 \mathrm{~N} \mathrm{HCl}$, respectively. To control for the effect of distension alone, the zero dose contained $0.15 \mathrm{M} \mathrm{NaCl}$ adjusted to $\mathrm{pH}$ 7.0. The meal was instilled in the stomach through the nasogastric tube by gravity over $3 \mathrm{~min}$. Gastric acid secretion was measured for 30 min by in vivo automatic intragastric titration at $\mathrm{pH} 7.0$ by the addition of $0.5 \mathrm{M} \mathrm{NaOH}$ (15). 30 min after the instillation of each meal, the gastric contents were completely aspirated, the recovered volumes measured to the nearest milliliter, the stomach lavaged with $100 \mathrm{ml}$ of 0.15 $\mathrm{M} \mathrm{NaCl}$, and the next meal instilled. Earlier studies indicated that intragastric administration of $8 \%$ peptone resulted in greatest secretory response and that the secretory responses to each dose were not significantly altered when the titration time of $30 \mathrm{~min}$ was extended to $45 \mathrm{~min}$ (14). Furthermore, the acid secretory responses did not differ significantly whether the test meals were given sequentially on a single day or individually in random order on separate days (14).

Measurement of serum gastrin. Serum gastrin was measured in response to both intravenous infusion of $\mathrm{G} 17$ and the intragastric peptone meals. Venous blood was obtained at 30-min intervals through an indwelling intravenous plastic catheter (Abbocath-T 20 gauge; Abbott Hospitals, Inc., North Chicago, IL). The blood was allowed to clot for $30 \mathrm{~min}$, centrifuged at $4^{\circ} \mathrm{C}$, and sera were stored at $-20^{\circ} \mathrm{C}$ for radioimmunoassay. Sera were measured in duplicate and the averages used. The antibody, 1611, was raised in rabbits immunized with G17 conjugated to bovine serum albumin (16). It was used in a final concentration of $1: 250,000$. This antibody is highly specific for both forms of gastrin (G17 and G34) and has < 3\% cross-reactivity with porcine cholecystokinin (16). With this antiserum, human G17 and human big gastrin (G34) were measured on a nearly equimolar basis (17).

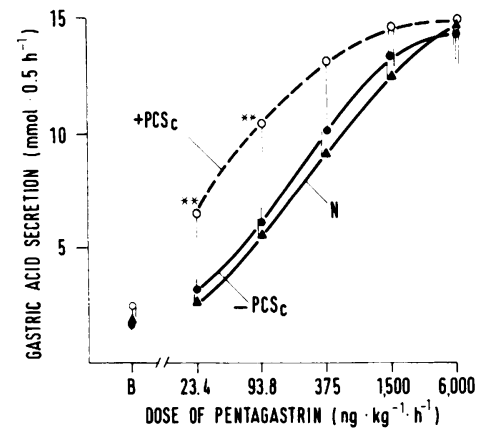

Figure 1. Gastric secretory rates at basal (B) and in response to graded doses of pentagastrin. In this and in subsequent figures, results obtained from $12+\mathrm{PCS}_{\mathrm{c}}$, $12-\mathrm{PCS}_{\mathrm{c}}$, and 12 normal subjects are expressed as the mean \pm SE unless indicated otherwise. **, $P<0.01$ compared with $-\mathrm{PCS}_{\mathrm{c}}$ and $(\mathrm{N})$.

Statistical analysis. Differences between treatment groups were determined by analysis of variance and the Neuman-Keuls multiple range test (18). Differences were considered significant if $P<0.05$. Results are expressed as means \pm SE. To calculate the dose that results in one-half maximal acid secretion dose $\left(\mathrm{ED}_{50}\right)$ for pentagastrin and $\mathrm{G} 17$ dose-response studies, linear regression analysis was performed according to the following equation: response $=$ calculated maximal response $-\mathrm{ED}_{50}$ (response/dose). $\mathrm{ED}_{50}$ is the negative slope of the equation. Since high basal values can give falsely low estimates of $\mathrm{ED}_{50}$ in dose-response studies, the basal-corrected $\mathrm{ED}_{50}\left(\mathrm{ED}_{50 \mathrm{c}}\right)$ was determined according to the following equation: $\mathrm{ED}_{50 \mathrm{c}}=\mathrm{ED}_{50}[1-(\mathrm{B} / \mathrm{M})]$, where $\mathrm{B}$ is basal rate of secretion and $M$ is calculated maximal response $+B(13,19)$. To estimate the plasma gastrin concentration that resulted in one-half maximal gastric acid secretion $\left(\mathrm{EC}_{50}\right)$, the individual gastric secretory responses after each dose of $\mathrm{G} 17$ or peptone were plotted against the corresponding plasma gastrin concentration. The $\mathrm{EC}_{50} \mathrm{~S}$ were derived from the individual curves.

\section{Results}

Effect of pentagastrin. Basal acid outputs were $2.5 \pm 0.7 \mathrm{mmol} /$ $0.5 \mathrm{~h}$ in $+\mathrm{PCS}_{\mathrm{c}}, 1.6 \pm 0.3 \mathrm{mmol} / 0.5 \mathrm{~h}$ in $-\mathrm{PCS}_{\mathrm{c}}$, and $1.8 \pm 0.3$ $\mathrm{mmol} / 0.5 \mathrm{~h}$ in $\mathrm{N}$. These differences were not significant. Maximal acid outputs were similar in the three groups (Fig. 1). In response to low doses of pentagastrin, acid secretion was significantly $(P<0.01)$ greater in + PCS $_{\mathrm{c}}$ compared with the two unshunted control groups. The secretory rates in response to each dose of pentagastrin were similar in $-\mathrm{PCS}_{\mathrm{c}}$ and $\mathrm{N}$ (Fig. 1). The mean dose of pentagastrin that was required to elicit one-half maximal gastric secretory responses was significantly lower in $+\mathrm{PCS}_{\mathrm{c}}$ compared with both the $-\mathrm{PCS}_{\mathrm{c}}$ and $\mathrm{N}$; regardless of whether the absolute or the basal-corrected values for gastric acid secretion were examined (Table I). No significant differences of the pentagastrin $\mathrm{ED}_{50} \mathrm{~s}$ were observed between $-\mathrm{PCS}_{\mathrm{c}}$ and $\mathrm{N}$.

Effect of G17. Basal acid outputs were not significantly $(P$

Table 1. Mean (+ SE) Doses of Pentagastrin $\left(n g \cdot \mathrm{kg}^{-1} \cdot \mathrm{h}^{-1}\right)$ to Elicit One-half Maximal Gastric Secretory Responses $\left(E D_{s a}\right)$

\begin{tabular}{llll}
\hline & $+\mathrm{PCS}_{\mathrm{c}}$ & $-\mathrm{PCS}_{\mathrm{c}}$ & $\mathrm{N}$ \\
\hline $\mathrm{ED}_{50}$ & $52.5 \pm 6.4$ & $133.9 \pm 25.5^{*}$ & $150.6 \pm 22.9^{\ddagger}$ \\
$\mathrm{ED}_{50_{c}}$ & $44.6 \pm 5.6$ & $121.4 \pm 23.6^{*}$ & $138.6 \pm 22.1^{\ddagger}$ \\
\hline
\end{tabular}

The subscript " $\mathrm{c}$ " in $\mathrm{ED}_{50}$ indicates that the individual data were corrected for basal acid secretion $(13,19)$. + PCS $_{\mathrm{c}}, 12+\mathrm{PCS}_{\mathrm{c}} ;-\mathrm{PCS}_{\mathrm{c}}, 12$ $-\mathrm{PCS}_{\mathrm{c}}$; and $\mathrm{N}, 12$ normal patients.

* $P<0.05$ compared with + PCS $_{\mathrm{c}}$.

${ }^{*} P<0.01$ compared with $+\mathrm{PCS}_{\mathrm{c}}$. 


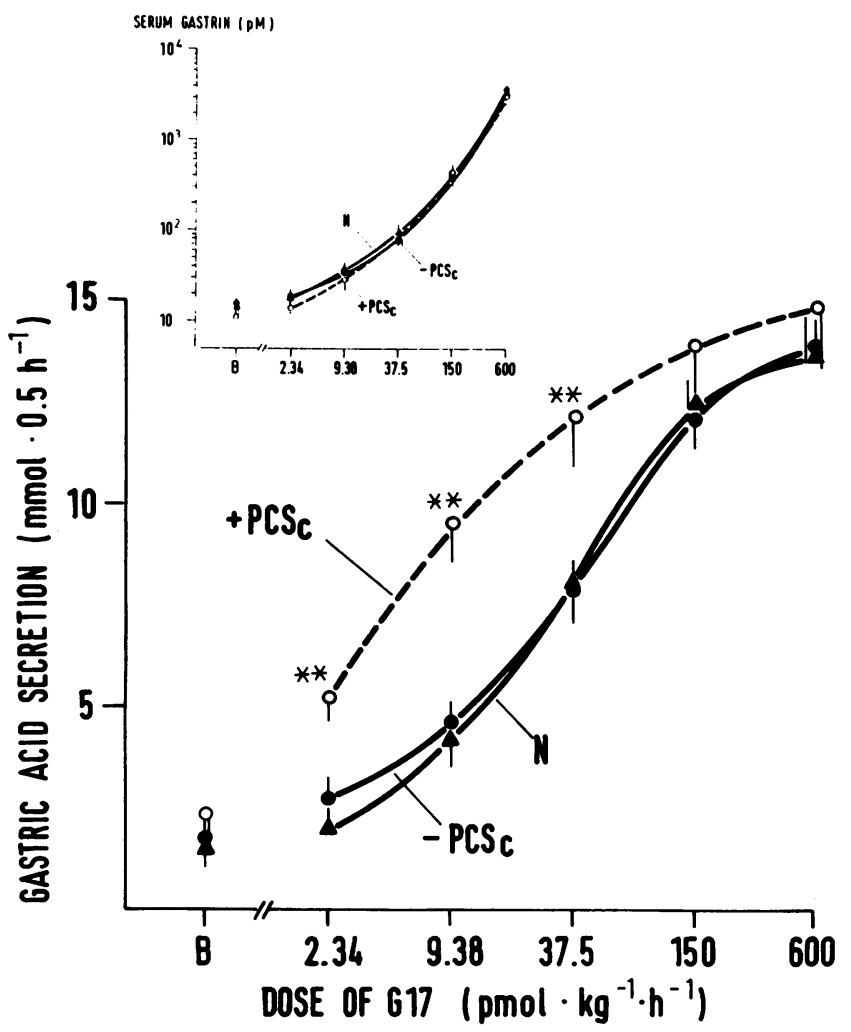

Figure 2. Gastric secretory rates and serum gastrin concentrations (inset) at basal (B) and in response to graded doses of human gastrin 17-I (G17) in $+\mathrm{PCS}_{\mathrm{c}},-\mathrm{PCS}_{\mathrm{c}}$, and N. **, $P<0.01$ compared with $-\mathrm{PCS}_{\mathrm{c}}$ and $\mathrm{N}$.

$>0.1)$ different in $+\mathrm{PCS}_{\mathrm{c}}(2.2 \pm 0.4),-\mathrm{PCS}_{\mathrm{c}}(1.6 \pm 0.4)$, and $\mathrm{N}$ $(1.5 \pm 0.4 \mathrm{mmol} / 0.5 \mathrm{~h})$ (Fig. 2). The maximal acid outputs to G17 were almost identical in $\mathrm{N}$ and $-\mathrm{PCS}_{\mathrm{c}}$, and were similar compared with the mean maximum acid output in the $+\mathrm{PCS}_{\mathrm{c}}$ (Fig. 2). Gastric acid secretion in response to the three lowest doses of $\mathrm{G} 17$ was significantly $(P<0.01)$ greater in the $+\mathrm{PCS}_{\mathrm{c}}$ group compared with the two $-\mathrm{PCS}_{\mathrm{c}}$ groups (Fig. 2).

Serum gastrin concentrations at basal and during intravenous infusion of $\mathrm{G} 17$ were similar in $+\mathrm{PCS}_{\mathrm{c}},-\mathrm{PCS}_{\mathrm{c}}$, and N (Fig. 2, inset). When the acid secretory responses were expressed in terms of the circulating serum gastrin concentrations (Fig. 3), the doseresponse curve in the $+\mathrm{PCS}_{\mathrm{c}}$ group was significantly shifted to the left. The plasma gastrin concentration following G17 that resulted in one-half maximal gastric acid secretion (EC $\mathrm{E}_{50}-\mathrm{G} 17$ ) was $19.5 \pm 2.3 \mathrm{pM}$ in $+\mathrm{PCS}_{\mathrm{c}}$ and significantly $(P<0.01)$ lower

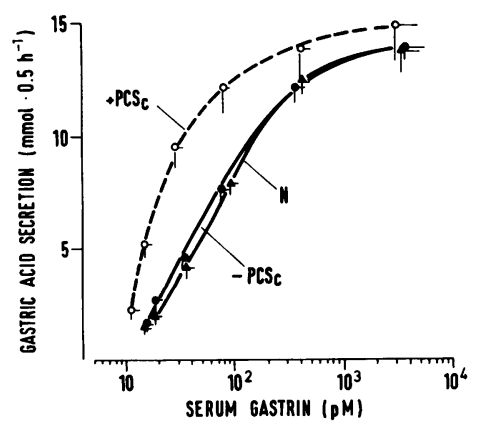

Figure 3. Comparison of the relationship between gastric acid secretion and serum gastrin concentrations after increasing doses of $\mathrm{G} 17$ in $+\mathrm{PCS}_{\mathrm{c}},-\mathrm{PCS}_{\mathrm{c}}$, and $\mathbf{N}$.

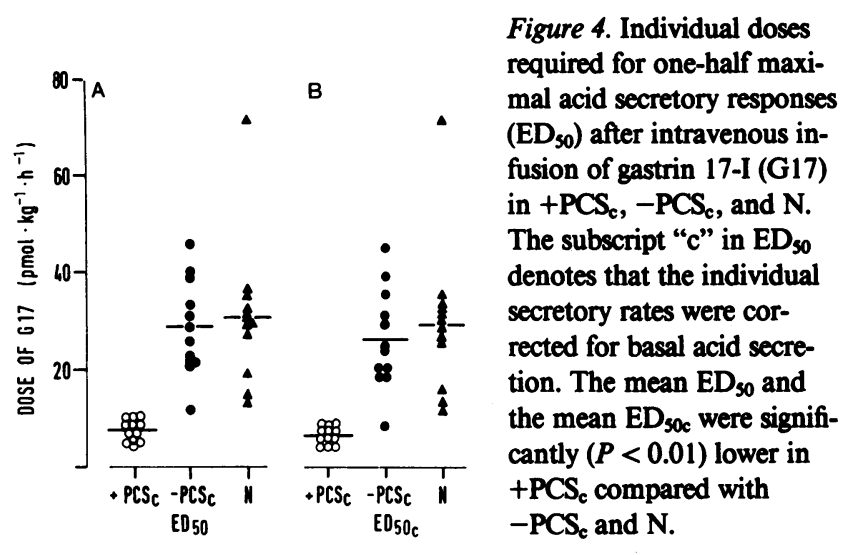

than the $\mathrm{EC}_{50}-\mathrm{G} 17$ in $-\mathrm{PCS}_{\mathrm{c}}(60.9 \pm 7.5 \mathrm{pM})$ and in $\mathrm{N}$ (68.4 $\pm 8.1 \mathrm{pM})$.

The dose of exogenous $\mathrm{G} 17$ required for one-half maximal acid secretory responses $\left(\mathrm{ED}_{50}\right)$ was $7.7 \pm 0.6$ in $+\mathrm{PCS}_{\mathrm{c}}, 28.3 \pm 2.8$ in $-\mathrm{PCS}_{\mathrm{c}}$, and $30.6 \pm 4.2 \mathrm{pmol} / \mathrm{kg}$ per $\mathrm{h}$ in the normal subjects $(P<0.01)$ (Fig. 4). Since basal secretion was numerically greater in those with portacaval shunt compared with those without portacaval shunt, the results were analyzed after subtracting basal acid outputs from the secretory responses to $\mathrm{G} 17$ in each individual subject. The mean $\mathrm{ED}_{50}$ corrected for basal $\left(\mathrm{ED}_{50 \mathrm{c}}\right)$ remained significantly $(P<0.01)$ different between + PCS $_{c}$ (6.4 \pm 0.5$)$ compared with $-\mathrm{PCS}_{\mathrm{c}}(26.3 \pm 3.0)$ and $\mathrm{N}(29.3 \pm 4.4$ pmol/kg per h) (Fig. 4 B).

Effect of peptone meals. On the meal test days, basal acid secretion was similar in cirrhotics with portacaval shunt compared with $-\mathrm{PCS}_{\mathrm{c}}$ and $\mathrm{N}, 2.3 \pm 0.2,1.5 \pm 0.2$, and $1.7 \pm 0.3$ $\mathrm{mmol} / 0.5 \mathrm{~h}$, respectively. Maximum acid outputs in response

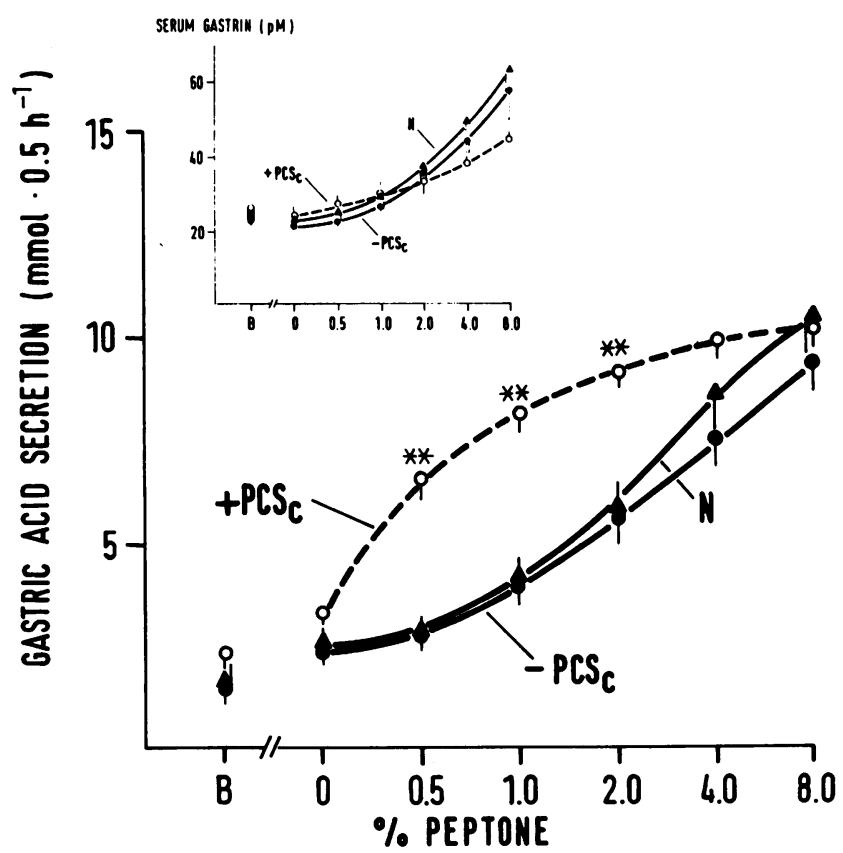

Figure 5. Gastric secretory rates and serum gastrin concentrations (inset) at basal (B) and in response to graded doses of intragastric peptone meals in $+\mathrm{PCS}_{\mathrm{c}},-\mathrm{PCS}_{\mathrm{c}}$, and N. **,P<0.01 compared with $-\mathrm{PCS}_{\mathrm{c}}$ and $\mathrm{N}$. 
to peptone were almost identical in the three groups (Fig. 5). After instillation of $0.15 \mathrm{M} \mathrm{NaCl}$ alone, as a control for distension, gastric acid secretion was comparable in the three groups (Fig. 5). However, as observed with exogenous G17 infusions, the dose-response curve to peptone was also significantly $(P$ $<0.01)$ shifted to the left in those with portacaval shunt. For example, the lowest dose of peptone $(0.5 \%)$ increased acid secretion to $58 \%$ of the maximal response in $+\mathrm{PCS}_{\mathrm{c}}$ compared with $30 \%$ in $-\mathrm{PCS}_{\mathrm{c}}$ and $28 \%$ in $\mathrm{N}$ (Fig. 5).

Serum gastrin concentrations before and after $0,0.5,1.0$, and $2.0 \%$ peptone were similar in the three groups (Fig. 5 , inset). The gastrin responses to 4.0 and $8.0 \%$ peptone were numerically, yet not significantly $(P>0.5)$, greater in the two unshunted control groups compared with $+\mathrm{PCS}_{\mathrm{c}}$.

When the individual serum gastrin concentrations after the test meals were related to the individual acid outputs, the curve of the $+\mathrm{PCS}_{\mathrm{c}}$. was significantly shifted to the left (Fig. 6). For example, a serum gastrin concentration of $35 \mathrm{pM}$ was associated with a near maximum secretory response to the meal in the $+\mathrm{PCS}_{\mathrm{c}}$, while in both the $-\mathrm{PCS}_{\mathrm{c}}$ and $\mathrm{N}$ the secretory response was $58 \%$ of maximum. The test meal that contained $0.15 \mathrm{M}$ $\mathrm{NaCl}(0 \%$ peptone) produced serum gastrin concentrations and acid secretory rates that were similar in the three groups (Fig. 6 , the lowest values in each group). However, at each gastrin concentration after the peptone meals, $+\mathrm{PCS}_{\mathrm{c}}$ secreted more acid than either of the two unshunted groups (Fig. 6). The plasma gastrin concentration after the peptone meals that resulted in one-half maximal acid secretion $\left(\mathrm{ED}_{50}\right.$-peptone) was $22.8 \pm 1.8$ $\mathrm{pM}$ in $+\mathrm{PCS}_{\mathrm{c}}$ and was significantly $(P<0.01)$ lower than the $\mathrm{ED}_{50}$-peptone in the $-\mathrm{PCS}_{\mathrm{c}}(31.7 \pm 2.6 \mathrm{pM})$ and in $\mathrm{N}$ $(34.9 \pm 2.6 \mathrm{pM})$.

\section{Discussion}

The results of this study indicate that (a) Basal gastric acid secretion was slightly, yet not significantly, greater in $+\mathrm{PCS}_{\mathrm{c}}$ compared with $-\mathrm{PCS}_{\mathrm{c}}$ and $\mathrm{N} ;(b)$ Maximal acid secretion in response to either pentagastrin, human gastrin 17-I (G17), or protein meals was similar in $+\mathrm{PCS}_{\mathrm{c}},-\mathrm{PCS}_{\mathrm{c}}$, and $\mathrm{N} ;(c)$ Gastric acid secretion was significantly more sensitive to exogenously administered pentagastrin or $\mathrm{G17}$, as well as to endogenously released gastrin in $+\mathrm{PCS}_{\mathrm{c}}$, compared with $-\mathrm{PCS}_{\mathrm{c}}$ and $\mathrm{N}$.

Maximal acid output in response to histamine was increased in dog after portacaval anastomosis (5). Prior studies in humans using histamine as the gastric agonist (6), and the present study, indicate that maximal acid output either in response to pentagastrin or $\mathrm{G} 17$ was similar in $+\mathrm{PCS}_{\mathrm{c}}$ compared with $-\mathrm{PCS}_{\mathrm{c}}$ and $\mathrm{N}$. These observations indicate that the total parietal cell mass is not increased in humans after portacaval shunt (12).

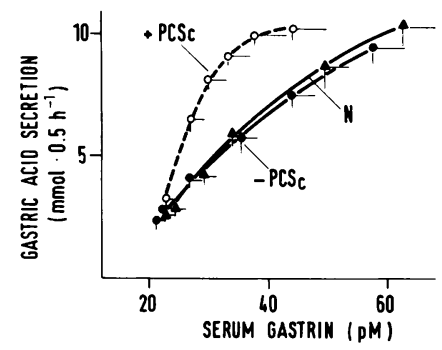

Figure 6. Comparison of the relationship between gastric acid secretion and serum gastrin concentrations after increasing doses of intragastric peptone meals in $+\mathrm{PCS}_{\mathrm{c}}$, $-\mathrm{PCS}_{\mathrm{c}}$, and $\mathrm{N}$.
Acid secretion in response to an intragastric meal was increased in dogs with separated gastric (Dr. Heidenhain) pouches after portacaval transposition (5), but has not previously been studied in humans. Our results demonstrate that acid output in response to a maximally stimulating dose of an intragastric peptone meal (14) was similar in $+\mathrm{PCS}_{\mathrm{c}},-\mathrm{PCS}_{\mathrm{c}}$, and in $\mathrm{N}$.

At pharmacologic serum gastrin concentrations, gastric acid secretion was similar in the shunted and unshunted subjects, while at physiological serum gastrin concentrations of $50 \mathrm{pM}$ and less (20), gastric acid secretion was significantly more sensitive to circulating gastrins in patients with portacaval shunt. It appears that the parietal cell in cirrhotic patients after portacaval shunt is exceedingly sensitive to gastrin. Increased sensitivity of the gastric mucosa to human gastrin has also been reported in the rat after portacaval shunt (21).

In $+\mathrm{PCS}_{\mathrm{c}}$, but not in $-\mathrm{PCS}_{\mathrm{c}}$ or $\mathrm{N}$, jejunal distension with a balloon or a hyperosmolar solution resulted in significant secretory responses $(6,8)$. It has been suggested that a humoral substance may be released from the small intestine that enhances gastric acid secretion when it bypasses the liver (22). The partial isolation of a nongastrin agonist of gastric acid secretion from the porcine small intestine referred to as the intestinal phase hormone or entero-oxyntin has been described $(22,23)$. It is possible that such a humoral agent, secreted by the human proximal small intestine and normally inactivated by the liver, functions as an agonist of acid secretion after portacaval shunt. This would explain the observation that in $+\mathrm{PCS}_{\mathrm{c}}$ the administration of low doses of peptone meals, that did not alter serum gastrin concentrations, resulted in significant increases in gastric acid secretion. Also, since stimulants of acid secretion, such as histamine and gastrin, resulted in a potentiated response when administered in combination (24), it is possible that an intestinal stimulant contributed to the increased sensitivity to intravenous pentagastrin and $\mathrm{G17}$, as well as to the peptone meals.

Portacaval shunt diverts mesenteric blood directly into the systemic circulation, bypassing the liver, which is one of many sites involved in gastrin metabolism (25). Therefore, higher levels of gastrin in the $+\mathrm{PCS}_{\mathrm{c}}$ could have mimicked the observed increased sensitivity. However, circulating gastrin levels were similar during intravenous infusion of G17 in those with and those without portacaval shunt. Also, gastrin fragments containing less than eight amino acids are preferentially removed by hepatic transit (10). Therefore, small circulating forms of gastrin not measurable by radioimmunoassay could result in the observed increased sensitivity to $\mathrm{Gl} 7$ and the peptone meals, as well as account for the slightly elevated basal secretion. If increased concentrations of small circulating gastrin fragments at basal were to cause the increased sensitivity to $\mathrm{G17}$, the additive effect of those molecular forms together with exogenous G17 could mimic the increased sensitivity. After subtracting the basal values, which, in part, may be due to small and large circulating forms of gastrin molecules, $+\mathrm{PCS}_{\mathrm{c}}$ were still more sensitive than the unshunted control groups. This suggests that increased concentrations of small gastrin fragments did not contribute to the hypersensitivity of $+\mathrm{PCS}_{\mathrm{c}}$ that was observed in response to exogenous G17. However, it is possible that peptone meals induced the release of small molecular forms of gastrin that were not detected by the radioimmunoassay. These gastrin fragments that are not removed by hepatic transit (10) could contribute to the increased sensitivity of gastric acid secretion to peptone meals in the $+\mathrm{PCS}_{\mathrm{c}}$. 
In summary, the results of this study indicate that gastric acid secretion is very sensitive to exogenously administered and endogenously released gastrin in $+\mathrm{PCS}_{\mathrm{c}}$ compared to $-\mathrm{PCS}_{\mathrm{c}}$ and $\mathrm{N}$. Increased sensitivity to gastrin may be due to the presence of an intestinal agonist of acid secretion that is normally inactivated within the liver. Other factors that may be released by intragastric peptone (e.g., small gastrin fragments) may also contributre to the increased sensitivity of meal-stimulated gastric acid secretion in + PCS $_{\mathrm{c}}$.

\section{Acknowledgments}

The authors thank Dr. Joseph Steinbach and Professor Rehpenning for statistical advice, Ms. Erika Friemel and Ms. Karin Feutlinske for technical assistance, Drs. Marshall J. Orloff and Richard Bell for referring some of the patients, and Ms. Nancy Hartung for preparation of the manuscript.

These studies were supported by the Deutsche Forschungsgemeinschaft (Le 470/1-2,3 and Le 470/2-1), the National Institutes of Arthritis, Metabolism and Digestive Disease (grants AM 17328 and AM 3349102), and by the Veterans Administration.

\section{References}

1. Pitcher, J. L. 1977. Variceal hemorrhage among patients with varices and upper gastrointestinal hemorrhage. South. Med. J. 70:11831185.

2. Orloff, M. J. 1981. The liver. In Textbook of Surgery. The Biological Basis of Modern Surgical Practice. D. C. Sabiston, Jr. and J. B. Duke, editors. W. B. Saunders \& Co., Philadelphia. 1131-1193.

3. Clarke, J. S., J. C. Hart, and R. S. Ozeran. 1958. Increase in heidenhain pouch secretion after portacaval transposition in the dog. Proc. Soc. Exp. Biol. Med. 97:118-121.

4. Silen, W., and B. Eiseman. 1959. The nature and cause of gastric hypersecretion following portacaval shunts. Surgery. 46:38-47.

5. Rex, J. C., C. F. Code, and W. H. ReMine. 1964. Gastric secretion of acid and urinary excretion of histamine in dogs with portacaval transposition. Ann. Surg. 160:193-201.

6. Orloff, M. J., J. G. Chandler, S. J. Alderman, J. E. Keiter, and H. Rosen. 1969. Gastric secretion and peptic ulcer following portacaval shunt in man. Ann. Surg. 170:515-524.

7. Ostrow, J. D., R. J. Timmerman, and S. J. Gray. 1960. Gastric secretion in human hepatic cirrhosis. Gastroenterology. 38:303-313.

8. Lenz, H. J., D. L. Hogan, and J. I. Isenberg. 1985. Intestinal phase of gastric acid secretion in humans with and without portacaval shunt. Gastroenterology. 89:791-796.

9. Lenz, H. J., T. Struck, D. P. Henry, Jr., and H. Greten. 1986.
Increased sensitivity to pentagastrin but not to histamine in cirrhotics with portacaval shunt. Gastroenterology. 90:1517. (Abstr.)

10. Strunz, U. T., M. R. Thompson, J. Elashoff, and M. I. Grossman. 1978. Hepatic inactivation of gastrins of various chain lengths in dogs. Gastroenterology. 74:550-553.

11. Conn, H. O. 1982. Cirrhosis. In Diseases of the Liver. L. Schiff and E. R. Schiff, editors. J. B. Lippincott Co., Philadelphia, 847-977.

12. Isenberg, J. I. 1978. Gastric secretory testing. In Gastrointestinal Disease: Pathophysiology, Diagnosis, Management. W. H. Sleisenger and J. S. Fordtran, editors. W. B. Saunders \& Co., Philadelphia. 714-732.

13. Isenberg, J. I., M. I. Grossman, V. Maxwell, and J. H. Walsh. 1975. Increased sensitivity to stimulation of acid secretion by pentagastrin in duodenal ulcer. J. Clin. Invest. 55:330-337.

14. Lam, S. K., J. I. Isenberg, M. I. Grossman, W. H. Lane, and J. H. Walsh. 1980. Gastric acid secretion is abnormally sensitive to endogenous gastrin released after peptone test meals in duodenal ulcer patients. J. Clin. Invest. 65:555-562.

15. Hogan, D. L., D. Turken, A. I. Stern, and J. I. Isenberg. 1983. Comparison of the serial dilution indicator and intragastric titration methods for measurement of meal-stimulated gastric acid secretion in man. Dig. Dis. Sci. 28:1001-1004.

16. Rosenquist, G. L., and J. H. Walsh. 1980. Radioimmunoassay of gastrin. In Gastrointestinal Hormones. G. B. Jerzy Glass, editor. Raven Press, New York. 769-795.

17. Eysselein, V. E., V. Maxwell, T. Reedy, E. Wünsch, and J. H. Walsh. 1984. Similar acid stimulatory potencies of synthetic human big and little gastrins in man. J. Clin. Invest. 73:1284-1290.

18. Zar, J. H. 1974. Biostatistical Analysis. Prentice-Hall, Inc., Englewood Cliffs. 1-620.

19. Grossman, M. I. 1973. What to do with basal in dose-response studies. A suggested answer. Gastroenterology. 65:341-344.

20. Richardson, C. T., J. H. Walsh, M. I. Hicks, and J. S. Fordtran. 1976. Studies on the mechanisms of food-stimulated gastric acid secretion in normal human subjects. J. Clin. Invest. 58:623-631.

21. Kutz, K., R. Herz, F. Halter, J. Leuenberger, and J. Bircher. 1974. Increased responsiveness of gastric mucosa to gastrin stimulation in the eck fistula rat. Gastroenterology. 66:73-78.

22. Orloff, M. J., P. V. B. Hyde, L. D. Kosta, R. C. L. Guillemin, and R. H. Bell. 1979. The intestinal phase hormone. World J. Surg. 3: 523-538.

23. Vagne, M., and V. Mutt. 1980. Entero-oxyntin: a stimulant of gastric acid secretion extracted from porcine intestine. Scand. J. Gastroenterol. 15:17-22.

24. Soll, A. H. 1981. Physiology of isolated canine parietal cells: receptors and effectors regulating function. In Physiology of the Gastrointestinal Tract. L. R. Johnson, editor. Raven Press, New York. 673691.

25. Strunz, U. T., J. H. Walsh, and M. I. Grossman. 1978. Removal of gastrin by various organs in dogs. Gastroenterology. 74:32-33. 